\title{
Characterization of the Kentville Stock Clone Apple Rootstocks. III. Quality and Overall Performance
}

\author{
C.G. Embree ${ }^{1}$, B.H. Lesser ${ }^{2}$, and A.D. Crowe ${ }^{3}$ \\ Research Station, Agriculture Canada, Kenville, N.S., B4N 1J5, Canada
}

Additional index words. Malus domestica, apple, rootstock, fruit quality

\begin{abstract}
The effects of 30 Kentville Stock Clone (KSC) selections on fruit size and color of 'McIntosh' and 'Delicious' apples (Malus domestica Borkh.) were monitored over 5 years. Fruit size was influenced by the rootstock and, when averaged over the duration of the study, ranged from 108 to $132 \mathrm{~g}$ and 131 to $161 \mathrm{~g}$ for 'McIntosh' and 'Delicious', respectively. Variation in fruit size due to crop load (CL) was greater for 'McIntosh' than for 'Delicious'. Fruit color was influenced by the rootstock in all years for 'McIntosh' and in 3 of 5 years for 'Delicious'; it was strongly associated with tree size for 'Delicious' only. An overall performance index, which also included price based on quality, was developed, and the best performers in each size group were: semidwarf KSC 18 and 28; semivigorous KSC 7, 11, and 24; and vigorous KSC 3 and 6.
\end{abstract}

The quality aspect of apple production is important to the commercial producer. Fruit size and color are major determinants of quality. Apple rootstocks have been found to affect fruit size (Alston, 1991; Autio, 1987; Autio, 1991; Blasco and Jackson, 1974; Jackson 1986; Preston, 1967; Prestonet al., 1981), although it is inconsistent over time (Lord et al. 1985) or varies with the cultivar (Wertheim, 1989). Dwarfing rootstocks have also been found to advance maturity and associated coloration in the fruit (Blasco and Jackson, 1974; Hewetson, 1944; Lord et al., 1985; Perry and Dilley, 1984). This result was confirmed by Autio (1987) using spur-type 'Delicious'; however, the dwarfing rootstock Mac 9 (Mark) slowed ripening compared to other rootstocks in this size category. These differences were only a few days in length, and other factors, such as yield and management practices, may also produce an effect of similar magnitude. The purpose of this work is to further characterize the KSC apple rootstocks by determining their influence on 'McIntosh' and 'Delicious' fruit quality. The overall performance of the KSC rootstocks is also reviewed, and superior performers in each size category are identified.

\section{Materials and Methods}

A random sample of 54 apples collected from each tree was graded manually for size and color. Size categories were $<60 \mathrm{~mm}$, 60 to $63 \mathrm{~mm}, 64$ to $70 \mathrm{~mm}$, and $>70 \mathrm{~mm}$. Average weight was determined by dividing sample weight by sample number. Color categories were $<1.5 \%$ red, $15 \%$ to $55 \%$ red, and $>55 \%$ red. Average color was calculated as the midrange of color for each category weighted by the fraction by weight of apples in that category. For each cultivar (separately), regression analysis was performed in which the relationship between average weight or average color and crop load (CL) was estimated in order to derive the percentage of variability explained by CL. Yearly CL was calculated as kilograms of fruit per square centimeter cross sectional area. In addition, the factor rootstock was introduced, and the significance probability of additional rootstock effects beyond that estimated as being due to CL was calculated.

Received for publication 6 Jan. 1992. Accepted for publication 25 Aug. 1992. Kentville Station Publication no. 2110. The cost of publishing this paper was defrayed in part by the payment of page charges. Under postal regulations, this paper therefore must be hereby marked advertisement solely to indicate this fact. ${ }^{1}$ Research Scientist.

${ }^{2}$ Research Scientist, term appointment.

${ }^{3}$ Research Scientist, retired.
For each sample, a quality index was determined by assigning to each size/color category a value reflecting its return in the marketplace. Top quality fruit suitable for count pack, fruit suitable for poly bags, and culls were assigned relative values of 1.0, 0.7 , and -0.34 , respectively. One price structure that would correspond to these values would be $\$ 15.00 / 20 \mathrm{~kg}$ for count fruit, $\$ 12.00 / 20 \mathrm{~kg}$ for poly bags, and $\$ 1.60 / 20 \mathrm{~kg}$ for culls, with $\$ 5.00 /$ $20 \mathrm{~kg}$ deducted for storage and packing expenses. The quality index was calculated as the sum over all size/color categories of the fraction by weight of fruit in each category multiplied by the relative value for that category.

\section{Results and Discussion}

Fruit weight. The average fruit weight for each cultivar/rootstock combination for fruit harvested in 1983-87 is shown in Table 1. For 'McIntosh', the 5-year mean fruit weight was highest for KSC 11 and smallest for KSC 28, and rootstock effects on fruit weight were significant $(P<0.05)$ in 4 of 5 years. For 'Delicious', the mean fruit weight for the 5 years was highest on KSC 1 and lowest on KSC 28, and there were rootstock effects on weight in all years. For both cultivars, there was no relationship between fruit weight and tree size.

To assess whether fruit weight differences were related to CL, regression analysis was performed. For 'McIntosh', variability in fruit weight due to CL ranged from $1.1 \%$ in 1983 to $17.9 \%$ in 1985 and 1986. Rootstock effects on fruit weight, beyond effects due to CL, were still significant $(P<0.05)$ for all years, except 1984 (P $=0.135)$ and $1986(P=0.443)$. For 'Delicious', $<9 \%$ of variability in fruit weight was due to CL differences, and rootstock effects on fruit weight remained significant in all years, except for $1984(P=$ $0.287)$ and $1986(P=0.190)$. Since 1984 and 1986 were the heavy cropping years of the biennial cycle, rootstock effects may have been masked by the higher CL.

Fruit color. For 'McIntosh', there were rootstock effects on color (Table 2). For 1984, 13.1\% of variability in color was related to CL differences, while for other years, the corresponding figure was $<5.3 \%$. In 1983 and 1985, rootstock effects on color remained significant $(P<0.05)$ despite CL variability, while in 1986 and $1987, P=0.080$ and 0.086 , respectively.

For 'Delicious', there were rootstock effects on color $(P<0.05)$ in 1983,1984 , and 1987 ; in $1985, P=0.079$. Only $4.2 \%$ or less of

Abbreviations: CL, crop load; KSC, Kentville Stock Clone. 
Table 1. Average fruit weight for each apple cultivar/KSC rootstock combination in order of increasing average tree size.

\begin{tabular}{|c|c|c|c|c|c|c|c|c|c|c|c|c|}
\hline \multirow{3}{*}{$\begin{array}{l}\text { KSC } \\
\text { (no.) }\end{array}$} & \multicolumn{11}{|c|}{ Wt per fruit (g) } & \multirow[b]{3}{*}{ Mean } \\
\hline & \multicolumn{6}{|c|}{ McIntosh } & \multicolumn{5}{|c|}{ Delicious } & \\
\hline & 1983 & 1984 & 1985 & 1986 & 1987 & Mean & 1983 & 1984 & 1985 & 1986 & 1987 & \\
\hline 28 & 118 & 136 & 134 & 117 & 87 & 108 & 145 & 131 & 164 & 123 & 146 & 131 \\
\hline 14 & 129 & 127 & 130 & 130 & 121 & 125 & 166 & 190 & 133 & 133 & 144 & 141 \\
\hline 26 & 129 & 134 & 144 & 112 & 116 & 120 & 144 & 169 & 145 & 128 & 134 & 142 \\
\hline 18 & 132 & 127 & 146 & 119 & 116 & 127 & 147 & 166 & 124 & 134 & 145 & 143 \\
\hline 23 & 137 & 129 & 140 & 111 & 130 & 127 & 142 & 168 & 147 & 128 & 151 & 147 \\
\hline 16 & 142 & 125 & 151 & 123 & 119 & 127 & 159 & 169 & 159 & 139 & 158 & 154 \\
\hline 4 & 132 & 143 & 131 & 120 & 146 & 129 & 160 & 190 & 142 & 135 & 146 & 143 \\
\hline 22 & 136 & 130 & 138 & 119 & 122 & 128 & 157 & 172 & 150 & 132 & 146 & 147 \\
\hline 24 & 144 & 140 & 130 & 117 & 113 & 123 & 155 & 181 & 146 & 141 & 153 & 147 \\
\hline 7 & 143 & 132 & 141 & 117 & 122 & 127 & 165 & 201 & 143 & 130 & 147 & 145 \\
\hline 19 & 137 & 132 & 144 & 112 & 100 & 120 & 156 & 178 & 145 & 122 & 147 & 143 \\
\hline 15 & 143 & 121 & 145 & 115 & 126 & 125 & 159 & 175 & 158 & 136 & 142 & 147 \\
\hline 9 & 151 & 136 & 147 & 123 & 104 & 124 & 151 & 171 & 138 & 133 & 137 & 140 \\
\hline 11 & 140 & 143 & 176 & 122 & 133 & 136 & 166 & 174 & 153 & 149 & 154 & 155 \\
\hline 25 & 138 & 131 & 149 & 113 & 111 & 123 & 151 & 180 & 146 & 136 & 149 & 147 \\
\hline 8 & 139 & 131 & 147 & 114 & 118 & 124 & 162 & 165 & 145 & 132 & 144 & 141 \\
\hline 29 & 142 & 126 & 129 & 118 & 121 & 122 & 148 & 170 & 132 & 144 & 143 & 142 \\
\hline 30 & 138 & 137 & 145 & 126 & 101 & 122 & 151 & 188 & 143 & 134 & 139 & 149 \\
\hline 12 & 142 & 135 & 152 & 118 & 124 & 129 & 160 & 180 & 146 & 140 & 154 & 152 \\
\hline 21 & 143 & 133 & 137 & 127 & 120 & 128 & 159 & 169 & 145 & 125 & 144 & 142 \\
\hline 13 & 142 & 137 & 152 & 119 & 129 & 132 & 159 & 172 & 145 & 135 & 152 & 148 \\
\hline 27 & 150 & 134 & 142 & 119 & 121 & 128 & 157 & 178 & 138 & 136 & 148 & 144 \\
\hline 20 & 131 & 130 & 136 & 119 & 108 & 120 & 151 & 176 & 142 & 138 & 137 & 140 \\
\hline 10 & 133 & 123 & 146 & 113 & 106 & 116 & 159 & 185 & 130 & 122 & 138 & 132 \\
\hline 17 & 150 & 142 & 153 & 119 & 125 & 132 & 164 & 163 & 143 & 121 & 148 & 139 \\
\hline 3 & 149 & 141 & 144 & 115 & 121 & 127 & 167 & 193 & 147 & 124 & 156 & 147 \\
\hline 1 & 134 & 133 & 140 & 119 & 124 & 124 & 168 & 186 & 152 & 150 & 162 & 161 \\
\hline 6 & 145 & 129 & 124 & 119 & 133 & 126 & 149 & 173 & 154 & 135 & 125 & 141 \\
\hline 5 & 137 & 141 & 146 & 142 & 120 & 132 & 169 & 184 & 162 & 141 & 146 & 148 \\
\hline 2 & 144 & 142 & 147 & 128 & 123 & 132 & 171 & 171 & 154 & 123 & 148 & 143 \\
\hline Mcan & 139 & 133 & 143 & 119 & 119 & 125 & 157 & 176 & 146 & 133 & 146 & 145 \\
\hline SEM & 4.2 & 5.3 & 6.0 & 5.0 & 7.2 & 3.0 & 5.5 & 10.0 & 6.4 & 6.0 & 5.2 & 3.2 \\
\hline $\operatorname{Pr}>F$ & 0.00 & 0.14 & 0.00 & 0.03 & 0.00 & 0.00 & 0.00 & 0.04 & 0.05 & 0.05 & 0.00 & 0.00 \\
\hline \multicolumn{13}{|c|}{ Percentage of variability due to $C L$} \\
\hline & 1.1 & 5.1 & 17.9 & 17.9 & 2.5 & & 1.4 & 6.5 & 8.7 & 3.8 & 0.9 & \\
\hline $\operatorname{Pr}>\mathrm{F}$ & 0.00 & 0.14 & 0.02 & 0.44 & 0.00 & & 0.01 & 0.29 & 0.00 & 0.20 & 0.02 & \\
\hline
\end{tabular}

variability in color was due to $\mathrm{CL}$ differences, and rootstock effects on color beyond CL effects were significant $(P<0.05)$ in all years.

For 'Delicious', the Spearman rank correlation coefficient between color and tree size was -0.70 , indicating a significant $(P$ $<0.01)$ reduction in color as tree vigor increased. For 'McIntosh', however, there was poor correlation between mean fruit color and tree size (Spearman rank correlation $=-0.32 ; P>0.05$ ). The inconsistency between 'Delicious' and 'McIntosh' may be partly explained by the poor color of the 'Delicious' strain.

Performance index. To assess the overall performance of 30 KSC rootstocks, each factor measured needs to be included and given appropriate weight. Only the first 10 years are included in the quality assessment because of severe fruit drop on 'McIntosh' just before harvest in 1988. Efficiencies for these lo-years were determined (Table 3). For each cultivar/rootstock combination, a mean quality index was calculated representing the mean of each year's quality index weighted by the crop density (apples per tree) in each yearrelative to the total crop density over the years. Finally, a performance index combining yield and quality was calculated as the product of efficiency and mean quality index. There were significant rootstock effects $(P<0.001)$ on all parameters. For 'McIntosh', the rootstocks with performance factors significantly higher than the average for all 30 rootstocks (in order of decreasing performance factor) were $\mathrm{KSC} 7, \mathrm{KSC} 6$, and KSC 3. For 'Delicious', the corresponding rootstocks were KSC 11, KSC 24, KSC 28, and KSC 7. Rootstocks with performance significantly lower than average (in order of increasing performance factor) were KSC 30 and KSC 19 for 'McIntosh' and KSC 27, KSC 20, and KSC 3 for 'Delicious'.

The performance index (Table 3 ) shows relative returns from the various cultivar/rootstock combinations. This index can be converted to a dollar value by multiplying by the net return for top quality fruit (e.g., $\$ 0.50 / \mathrm{kg}$ ) and to returns per hectare by multiplying again by the average square centimeter of trunk cross-section per hectare. If trees of varying sizes were spaced in proportion to their size, then this number would be independent of tree size. 
Table 2. Average percent red color for each cultivar/KSC rootstock combination in order of increasing average tree size.

\begin{tabular}{|c|c|c|c|c|c|c|c|c|c|c|c|c|}
\hline \multirow{3}{*}{$\begin{array}{l}\text { KSC } \\
\text { (no.) }\end{array}$} & \multicolumn{11}{|c|}{ Red color $(\%))$} & \multirow[b]{3}{*}{ Mean } \\
\hline & \multicolumn{6}{|c|}{ McIntosh } & \multicolumn{5}{|c|}{ Delicious } & \\
\hline & 1983 & 1984 & 1985 & 1986 & 1987 & Mean & 1983 & 1984 & 1985 & 1986 & 1987 & \\
\hline$\overline{28}$ & 74 & 65 & 55 & 77 & 54 & 62 & 65 & 59 & 39 & 49 & 62 & 53 \\
\hline 14 & 78 & 72 & 62 & 73 & 56 & 64 & 76 & 63 & 43 & 51 & 67 & 52 \\
\hline 26 & 76 & 63 & 61 & 74 & 56 & 66 & 71 & 69 & 39 & 46 & 64 & 54 \\
\hline 18 & 76 & 64 & 61 & 74 & 57 & 65 & 69 & 63 & 31 & 51 & 61 & 53 \\
\hline 23 & 73 & 57 & 55 & 74 & 52 & 61 & 69 & 67 & 37 & 45 & 63 & 52 \\
\hline 16 & 71 & 64 & 59 & 74 & 53 & 63 & 52 & 50 & 36 & 44 & 51 & 45 \\
\hline 4 & 74 & 64 & 51 & 71 & 59 & 63 & 66 & 62 & 38 & 45 & 59 & 50 \\
\hline 22 & 77 & 66 & 56 & 73 & 55 & 65 & 62 & 60 & 38 & 46 & 59 & 51 \\
\hline 24 & 67 & 55 & 45 & 65 & 49 & 56 & 59 & 54 & 39 & 44 & 53 & 48 \\
\hline 7 & 66 & 53 & 50 & 64 & 47 & 58 & 56 & 48 & 36 & 44 & 58 & 47 \\
\hline 19 & 71 & 55 & 56 & 73 & 58 & 62 & 65 & 62 & 39 & 47 & 58 & 50 \\
\hline 15 & 68 & 59 & 52 & 72 & 56 & 62 & 71 & 60 & 50 & 55 & 63 & 63 \\
\hline 9 & 77 & 63 & 65 & 75 & 61 & 63 & 61 & 43 & 36 & 44 & 55 & 46 \\
\hline 11 & 66 & 55 & 47 & 71 & 56 & 61 & 64 & 56 & 39 & 47 & 56 & 50 \\
\hline 25 & 73 & 60 & 56 & 74 & 53 & 64 & 67 & 56 & 41 & 45 & 53 & 50 \\
\hline 8 & 74 & 63 & 62 & 76 & 55 & 64 & 70 & 59 & 46 & 44 & 65 & 53 \\
\hline 29 & 75 & 54 & 55 & 74 & 49 & 60 & 63 & 56 & 40 & 43 & 57 & 50 \\
\hline 30 & 72 & 57 & 57 & 76 & 61 & 63 & 66 & 63 & 39 & 50 & 62 & 52 \\
\hline 12 & 72 & 60 & 55 & 75 & 52 & 62 & 56 & 50 & 36 & 42 & 59 & 46 \\
\hline 21 & 76 & 60 & 58 & 73 & 57 & 63 & 65 & 53 & 38 & 46 & 60 & 49 \\
\hline 13 & 70 & 57 & 55 & 68 & 54 & 60 & 60 & 53 & 37 & 44 & 60 & 48 \\
\hline 27 & 75 & 63 & 55 & 75 & 54 & 64 & 69 & 60 & 37 & 44 & 60 & 50 \\
\hline 20 & 76 & 63 & 61 & 75 & 62 & 65 & 70 & 64 & 38 & 46 & 62 & 51 \\
\hline 10 & 69 & 58 & 55 & 76 & 57 & 63 & 66 & 54 & 36 & 40 & 59 & 46 \\
\hline 17 & 66 & 57 & 55 & 72 & 52 & 61 & 55 & 48 & 35 & 41 & 50 & 44 \\
\hline 3 & 71 & 61 & 56 & 76 & 56 & 59 & 60 & 49 & 35 & 48 & 57 & 47 \\
\hline 1 & 76 & 61 & 59 & 74 & 55 & 64 & 63 & 59 & 45 & 46 & 64 & 50 \\
\hline 6 & 68 & 52 & 56 & 73 & 51 & 61 & 65 & 58 & 43 & 49 & 51 & 45 \\
\hline 5 & 66 & 59 & 55 & 70 & 50 & 59 & 56 & 52 & 37 & 46 & 60 & 48 \\
\hline 2 & 68 & 54 & 52 & 73 & 51 & 59 & 58 & 59 & 37 & 46 & 52 & 48 \\
\hline Mean & 72 & 60 & 56 & 73 & 55 & 62 & 64 & 57 & 39 & 46 & 59 & 50 \\
\hline SEM & 2.0 & 3.4 & 2.9 & 1.7 & 2.8 & 1.4 & 2.9 & 4.2 & 3.0 & 2.8 & 2.7 & 1.7 \\
\hline $\operatorname{Pr}>\mathrm{F}$ & 0.00 & 0.02 & 0.00 & 0.00 & 0.03 & 0.00 & 0.00 & 0.00 & 0.08 & 0.16 & 0.00 & 0.00 \\
\hline \multicolumn{13}{|c|}{ Percentage of variability due to $C L$} \\
\hline & 4 & 13 & 0 & 5 & 5 & & 4 & 0 & 2 & 1 & 3 & \\
\hline $\operatorname{Pr}>F$ & 0.00 & 0.62 & 0.02 & 0.08 & 0.09 & & 0.00 & 0.00 & 0.02 & 0.03 & 0.00 & \\
\hline
\end{tabular}

The performance of the two cultivars was not consistent on some rootstocks. For example, 'McIntosh' performed well on KSC 3, while 'Delicious' performed poorly on this rootstock. Since the current study was designed to test rootstock differences and was not randomized by cultivar, this observation warrants further investigation. If it is borne out, it indicates the importance of finding universal criteria for evaluating rootstock performance and the need for finding new ways to predict cultivar/rootstock synergism.

Summary. Tree growth, precocity, yield, and fruit quality are important components of apple tree performance in the field. This study documents field performance of these components for the $\mathrm{KSC}$ rootstock candidates with two cultivars and proposes methods that promise to more clearly quantify and reduce the time required to identify superior rootstock.

Differences in final tree size could be projected by the end of the sixth season. There was a substantial range in tree size, and by extrapolation was estimated to be from $\approx 25 \%$ smaller to $55 \%$ larger than MM. 106. There was good correlation between three methods of assessing tree size: trunk cross-section area, top weight, and top weight plus accumulated weight of prunings. First fruits were borne in the third season. 'McIntosh' was $60 \%$ more efficient in production than 'Delicious' (Embree et. al., 1993).

Methods of determining real productivity (independent of tree size and biennial bearing, yet weighing precocity) were developed. Precocity and productivity were not correlated. Therefore, cropping performance ratings for stocks must be delayed until mature production has been achieved. In this trial, the minimum was $\approx 8$ years; some stocks required the full 10 years and may not have completely stabilized. There was no correlation between cropping performance and tree size (Lesser et al., 1993).

Fruit size and fruit color were significantly affected by the rootstock even after adjustment for CL, but the magnitude was much less than for tree size and cropping efficiency.

A productivity index, based on efficiency, fruit quality, and a subjective price grade differential, was developed. On this basis 
Table 3. Efficiency after 10 years, mean quality index, and performance index for each apple cultivar/KSC rootstock combination in order of increasing average tree size. Means and SE were determined by analysis of variance for each cultivar separately.

\begin{tabular}{|c|c|c|c|c|c|c|}
\hline \multirow[b]{2}{*}{$\begin{array}{l}\text { KSC } \\
\text { (no.) }\end{array}$} & \multicolumn{3}{|c|}{ McIntosh } & \multicolumn{3}{|c|}{ Delicious } \\
\hline & $\begin{array}{c}\text { Efficiency } \\
\text { year } 10 \\
\left(\mathrm{~kg} \cdot \mathrm{cm}^{-2}\right)\end{array}$ & $\begin{array}{l}\text { Mean } \\
\text { quality } \\
\text { index }\end{array}$ & $\begin{array}{l}\text { Performance } \\
\text { index }\end{array}$ & $\begin{array}{c}\text { Efficiency } \\
\text { year } 10 \\
\left(\mathrm{~kg} \cdot \mathrm{cm}^{-2}\right)\end{array}$ & $\begin{array}{c}\text { Mean } \\
\text { quality } \\
\text { index }\end{array}$ & $\begin{array}{l}\text { Performance } \\
\text { index }\end{array}$ \\
\hline 28 & 4.08 & 0.747 & 3.20 & 3.12 & $0 . \overline{773}$ & 2.38 \\
\hline 14 & 3.32 & 0.873 & 2.90 & 1.93 & 0.802 & 1.56 \\
\hline 26 & 3.51 & 0.858 & 3.01 & 2.14 & 0.806 & 1.83 \\
\hline 18 & 3.92 & 0.869 & 3.40 & 2.73 & 0.800 & 2.20 \\
\hline 23 & 3.69 & 0.845 & 3.07 & 2.28 & 0.802 & 2.05 \\
\hline 16 & 3.94 & 0.860 & 3.37 & 2.72 & 0.767 & 2.18 \\
\hline 4 & 3.93 & 0.861 & 3.38 & 2.35 & 0.789 & 1.84 \\
\hline 22 & 3.66 & 0.866 & 3.18 & 2.07 & 0.794 & 1.68 \\
\hline 24 & 4.07 & 0.804 & 3.25 & 3.35 & 0.780 & 2.54 \\
\hline 7 & 4.89 & 0.815 & 4.02 & 2.80 & 0.772 & 2.25 \\
\hline 19 & 3.14 & 0.822 & 2.59 & 1.97 & 0.785 & 1.60 \\
\hline 15 & 4.20 & 0.848 & 3.53 & 2.49 & 0.850 & 2.15 \\
\hline 9 & 3.40 & 0.851 & 2.92 & 2.14 & 0.761 & 1.69 \\
\hline 11 & 3.97 & 0.852 & 3.37 & 3.19 & 0.797 & 2.58 \\
\hline 25 & 3.84 & 0.842 & 3.22 & 2.29 & 0.780 & 1.79 \\
\hline 8 & 3.32 & 0.861 & 2.86 & 2.12 & 0.800 & 1.94 \\
\hline 29 & 3.43 & 0.819 & 2.98 & 1.79 & 0.789 & 1.44 \\
\hline 30 & 2.95 & 0.837 & 2.37 & 2.17 & 0.805 & 1.58 \\
\hline 12 & 3.77 & 0.840 & 3.17 & 2.54 & 0.768 & 1.86 \\
\hline 21 & 3.82 & 0.866 & 3.31 & 2.26 & 0.783 & 1.80 \\
\hline 13 & 3.94 & 0.840 & 3.26 & 2.58 & 0.782 & 1.95 \\
\hline 27 & 3.45 & 0.861 & 2.97 & 1.78 & 0.795 & 1.41 \\
\hline 20 & 3.32 & 0.849 & 2.83 & 1.86 & 0.793 & 1.43 \\
\hline 10 & 3.68 & 0.836 & 3.10 & 2.14 & 0.758 & 1.61 \\
\hline 17 & 3.86 & 0.848 & 3.27 & 2.48 & 0.749 & 1.82 \\
\hline 3 & 4.49 & 0.837 & 3.77 & 2.29 & 0.777 & 1.68 \\
\hline 1 & 3.83 & 0.847 & 3.24 & 2.14 & 0.799 & 1.77 \\
\hline 6 & 4.56 & 0.841 & 3.83 & 2.79 & 0.752 & 2.15 \\
\hline 5 & 3.72 & 0.845 & 3.15 & 2.31 & 0.779 & 1.83 \\
\hline 2 & 3.37 & 0.845 & 2.85 & 2.01 & 0.780 & 1.57 \\
\hline Mean & 3.77 & 0.843 & 3.18 & 2.36 & 0.786 & 1.87 \\
\hline SEM & 0.195 & 0.0108 & 0.164 & 0.168 & 0.0090 & 0.128 \\
\hline
\end{tabular}

there were nine superior and nine inferior stocks. Size classification of the superior ones was: KSC 28 and 18, semidwarf; KSC 7, 11, 15, 16, and 24, semivigorous; KSC 3 and 6 vigorous. (The KSC rootstocks 15 and 16 show high performance values; however, field mortality with 'McIntosh' was high and, therefore, they are not recommended for further study at this time). The methods of evaluating field performance of apple rootstocks illustrated in this series of papers have potential for accelerating the screening process. We recognize that these methods need additional testing over a wider range of conditions.

\section{Literature Cited}

Alston, F.H. 1991. Pip fruits, the prospects of obtaining better scion varieties and rootstocks. Professional Hort. 5:23-27.

Autio. W.R. 1987. Effects of rootstock on apple ripening, size and quality. Compact Fruit Tree 20:98-102.

Autio, W.R. 1991. Rootstocks affect ripening and other qualities of

'Delicious' apples. J. Amer. Soc. Hort. Sci. 116:378-382.

Blasco, A.B. and J.E. Jackson. 1974. Rootstockinfluence oncropping and fruit quality. Proc. 19th Intl. Hort. Congr. 1B:585.

Embree, C.G., B.H. Lesser, and A. D. Crowe. 1993. Characterization of the Kentville Stock Clone apple rootstocks. I. Growth and efficiency. J. Amer Soc. Hort. Sci. 118:170-172.

Hewetson, F.N. 1944. Growth and yield of 'McIntosh' apple trees as influenced by the use of various intermediate stem pieces. Proc. Amer. Soc. Hort. Sci. 45:181-186

Jackson, J.E. 1986. Malling 20 - A super-dwarf rootstock for apples. Acta Hort. 160:4748.

Lesser, B.H., C.G. Embree, and A.D. Crowe. 1993. Characterization of the Kentville Stock Clone apple rootstocks. II. Precocity and productivity. J. Amer Soc. Hort. Sci. 118:173-176.

Lord, W.J., D.W. Greene, R.A. Damon, Jr., and J.H. Baker. 1985. Effects of stempiece and rootstock combinations on growth, leaf mineral concentrations, yield, and fruit quality of 'Empire' apple trees. J. Amer. Soc. Hort. Sci. 110:422425.

Perry, R.L. and D.R. Dilley. 1984. The influence of interstem on ripening indicies of 'Empire' apples. Compact Fruit Tree 17:50-54.

Preston, A.P. 1967. Apple rootstock studies; fifteen years' results with some M.IX crosses. J. Hort. Sci. 42:41-50.

Preston, A.P., D.E. Belcher, and B.C. Ley. 1981. Apple rootstock studies: Bramley seedling on dwarfing clones. Expt. Hort. 32: 18-24.

Wertheim, S.J. 1989. Preliminary results of trials withdwarfing apple and pear rootstocks. Acta Hort. 243:59-70. 